\title{
RAPID BIPLANE ANGIOCARDIOGRAPHY IN THE TETRALOGY OF FALLOT
}

\author{
BY \\ J. HILARIO,* J. LIND, AND C. WEGELIUS \\ From the Pediatric Clinic of the Caroline Institute (Prof. A. Wallgren) and the \\ Wenner-Gren Cardiovascular Research Laboratory, Stockholm
}

Received July 20, 1953

Surgery of the heart is becoming increasingly intracardiac; it is, therefore, more important than ever to gain an accurate knowledge of the anatomical and functional changes during the whole of the cardiac cycle, before operative treatment is contemplated.

In Fallot's tetralogy interest has chiefly been centred on the outflow tract of the right ventricle. The prognosis as well as the indications for operation depend to a large extent on the functional capacity of this chamber. This information has been gained primarily by catheterization of the heart and the results have been correlated with the morphological studies obtained by means of angiocardiography. However, there has often been some discrepancy in the results obtained with these two different methods of examination and diagnosis. Even when the results of a necropsy are available the anatomy and the function have often markedly disagreed. The necropsy findings naturally vary with the stage of rigor mortis. In the angiocardiographic examinations often only one picture, or at the most only two separate pictures, of each visualized heart chamber are obtained, and, furthermore, the information thus obtained portrays the static anatomy of the heart. In order to get a wide knowledge of the dynamics of the heart, it is imperative to carry out a continuous objective recording of this organ in life. Such a large part of the intricate heart mechanism is intrinsic to the heart that an accurate concept of its activity is made difficult if one studies merely the movements of the heart silhouette by kymography or even directly at operation.

Various reports on the rapid method of angiocardiography with synchronous photography in two projections at right angles and simultaneous electrocardiographic recordings have been presented previously from Norrtulls Hospital and its advantages in the study of heart disease have been pointed out. This report is based on an angiocardiographic study of 23 cases of Fallot's tetralogy using the rapid biplane method. A short review of anatomical and patho-physiological aspects of this disease is presented, and following this a discussion of the importance relative to surgical treatment.

\section{Material AND Methods}

Twenty-three unselected cases of Fallot's tetralogy, of which all were under 10 years of age and most were less than 3 years of age, were studied with rapid angiocardiographic methods at the Radiology Department of Norrtulls Hospital. The diagnosis was based on the clinical examination, including electrocardiography and angiocardiography, but the children were not catheterized.

The technique of the angiocardiographic method used has been reported elsewhere (Fredzell et al., 1950). Umbradil (70\% astra) was injected as a contrast medium via the superior route (antecubital vein) in the early cases. Later, the site of injection was changed to the greater saphenous vein at the ankle. * Working in Norrtulls Hospital under a Fellowship of National Research Council of Brazil. 
This was done to avoid the projection of a contrast-filled superior vena cava overlying the aorta, to minimize pressure differences created in the atria, and to increase the chance of visualizing an atrial septal patency (Lind and Wegelius, 1953). Taking into account the increased risk of angiocardiography in those cases with an overriding aorta the dosage of contrast medium has been kept low (1-1.25 ml. per $\mathrm{kg}$. of body weight). Two projections were obtained simultaneously and instead of the previously employed anterior-posterior and lateral projections, two lateral oblique views were obtained for a better appreciation of morphology. Each case was examined jointly by each member of the team in order to correlate clinical, radiological, and surgical observations.

\section{RESULTS}

The Venous'Return. The anatomical course of the venous return and some aspects of its drainage into the right atrium can be shown with this method. The site of injection was a superior route in 16 cases and the inferior route in the remainder.

In this series, with the exception of one case, the superior and inferior vena cava followed their normal pattern of drainage into the right atrium. In this one (Case 18) the inferior vena cava showed an anomalous pattern with drainage into the left atrium. Where the superior route was used for injection the superior vena cava was found to be dilated in 13 of the cases (Fig. 1, 4, 5, and 6); in 3 its calibre was considered normal. This dilatation was found to be present also in the inferior vena cava in 4 out of 7 cases in which it was visualized.

A retrograde filling of adjacent vessels with the contrast medium during atrial systole was observed when using the superior as well as the inferior route. The route by which the dye was injected had no influence on this reflux.

There was generally a moderate reflux of contrast medium (14 cases) and it was marked in 4

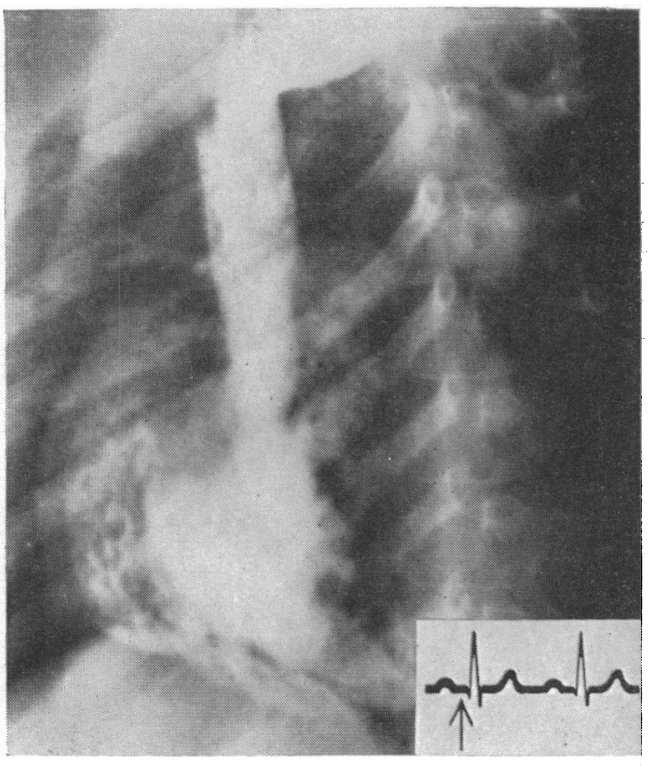

FIG. 1.-Hypertrophy of the right ventricle. Injection through the left antecubital vein. Left anterior oblique projection (L.A.O.). At the end of atrial systole the thickness of the right ventricular wall can be judged best in this projection. In this case hypertrophy as well as increased trabeculation of the ventricular wall can be seen.

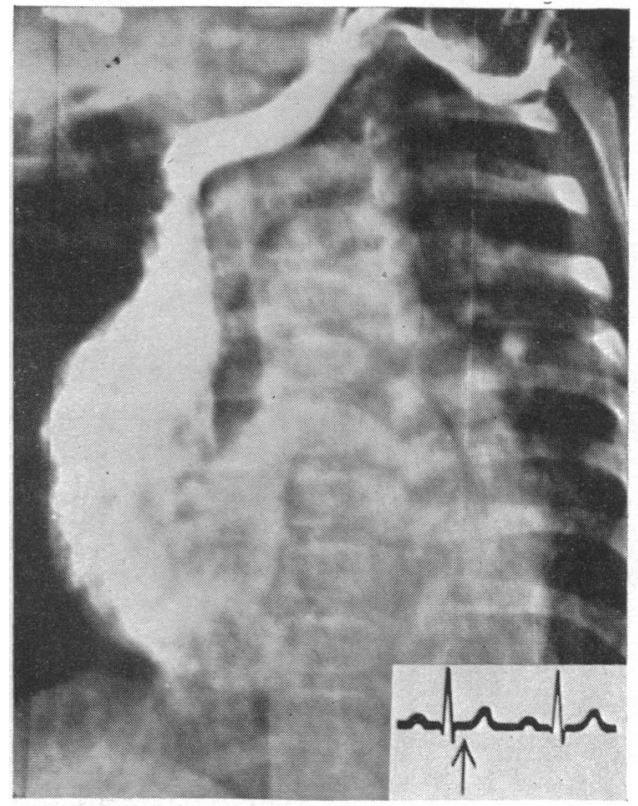

Fig. 2.-Interventricular shunt. Direct demonstration of an interventricular shunt. Injection through the left antecubital vein (L.A.O.). At the beginning of the first ventricular systole a right-to-left interventricular shunt is directly shown. The size of the defect and its localization high up in the septum is seen. A right-to-left interatrial shunt could be excluded in the previous pictures. 
cases. Generally this reflux was into the inferior vena cava and the suprahepatic veins, and only in two cases into the superior vena cava. The venous reflux always appeared during atrial systole (Fig. 4).

Right Atrium. In all cases the right atrium was enlarged with an accompanying dilatation of its appendage (Fig. 3, 5, 6, and 7). The greatest enlargement was found in association with an atrial septal patency. It was sufficient to cause the right atrium to assume a more rounded contour in 9 cases. The amount of residual dye was considered above normal in 12 cases.

The presence of a right-to-left shunt of the dye was demonstrated in 8 cases: this would indicate a high frequency of atrial septal patencies in Fallot's tetralogy. This shunt was considered to be small in 5 , moderate in 1 , large in 2 , and questionable in one other.
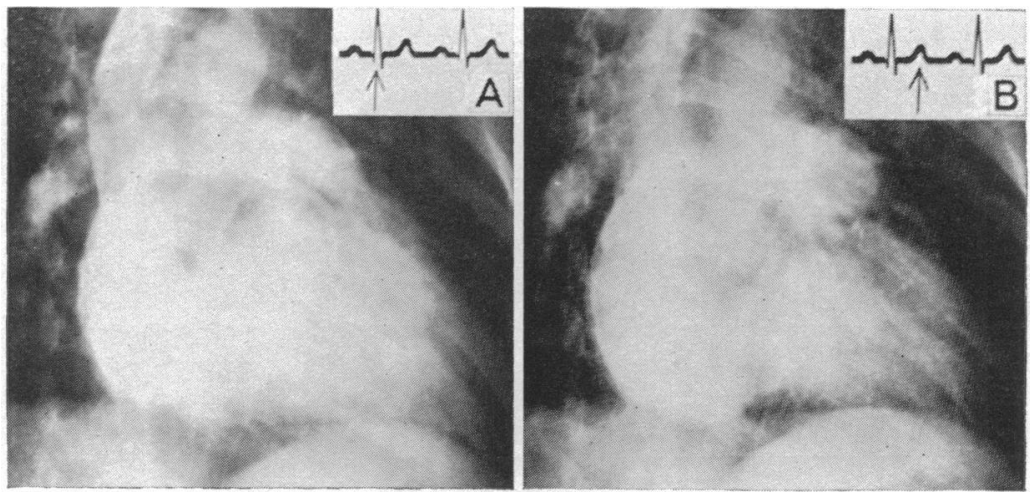

FIG. 3.-Low infundibular stenosis. Infundibular chamber. Injection through the right antecubital vein. Right anterior oblique projection (R.A.O.). (A) Superior vena cava and right atrium somewhat dilated. Pulmonary artery and aorta contrast-filled simultaneously. Infundibular stenosis. (B) In the following ventricular systole the low infundibular stenosis is clearly seen. The infundibulum is apparently shut at this point. There is a dilatation of the infundibular chamber, suggesting some degree of valvular stenosis.
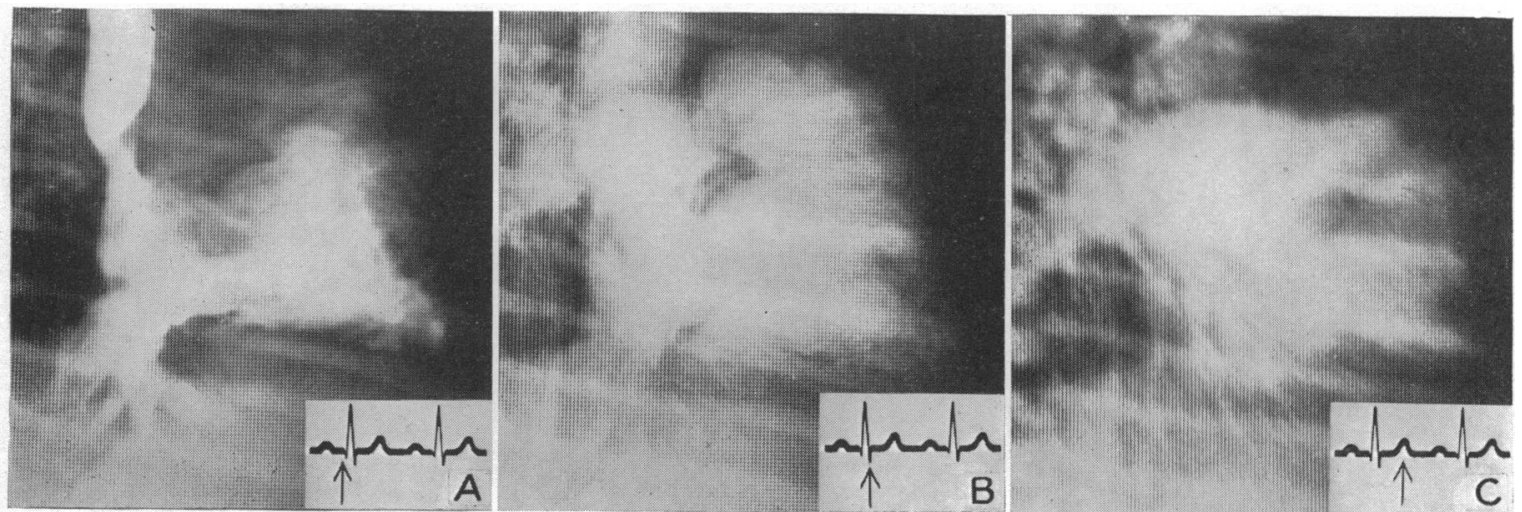

FIG. 4.-Valvular stenosis. Injection through the right antecubital vein (R.A.O.). Verified at operation. (A) Superior vena cava moderately dilated. In atrial systole a contraction of the proximal part of vena cava as well as a reflux down into the inferior vena cava. At the same time contrast medium is streaming into the right ventricle. (B) End of atrial systole. Right ventricle is dilated, especially the infundibulum. There is a slight dilatation of the pulmonary artery. Aorta is clearly seen. (C) At the end of ventricular systole there is seen a great increase in the bulging of the post-stenotic dilatation. There is still good passage through the infundibulum instead of a reduction of its calibre. 
Right Ventricle. In 20 cases a fairly good opacification of the right ventricle was obtained but in 3 it was poor. The ventricle was enlarged in all but one which showed hypertrophy of the wall rather than dilatation of the chamber.

The amount of residual dye was increased above normal in 13 cases (Fig. 3, 4, and 6). In 2 the results were inconclusive. The hypertrophy of the wall of the right ventricle was clearly demonstrated in 12 cases (Fig. 1). In 9 there was assumed to be hypertrophy because of the trabeculated appearance of the wall and one was questionable. A right-to-left interventricular shunt of dye was not observed in 10 but its presence was demonstrated in 12 (Fig. 2); it was classified as large in 2 , moderate in 6 , and small in 4 cases.

The Pulmonary Infundibulum (Table I). The opacification of the pulmonary infundibulum was found to be fairly good in 10 cases, poor in 11 , and in the remaining 2 identification of the pulmonary conus proved difficult. One of these was Case 18 and the other was associated with a patent ductus arteriosus, and we presumed the existence of an infundibular aplasia.

It was possible to outline the anatomical form of the pulmonary conus in 15 cases. We gained the impression that in the right anterior oblique position (which is best for its visualization) it generally possessed a greater diameter and a more cylindrical shape than in the left anterior oblique

TABLE I

Form AND WidTh OF THE PUlmonary INFUNDIBULUM

\begin{tabular}{|c|c|c|c|c|c|c|c|c|}
\hline No. & $\begin{array}{l}\text { Opacifica- } \\
\text { tion }\end{array}$ & $\begin{array}{l}\text { Diastolic } \\
\text { form }\end{array}$ & $\begin{array}{l}\text { Systolic } \\
\text { form }\end{array}$ & $\begin{array}{l}\text { Nature of } \\
\text { stenosis }\end{array}$ & $\begin{array}{l}\text { Length } \\
\text { in systole }\end{array}$ & $\begin{array}{l}\text { Width } \\
\text { in systole }\end{array}$ & $\begin{array}{c}\text { Width } \\
\text { in diastole }\end{array}$ & $\begin{array}{l}\text { Completely } \\
\text { shut at } \\
\text { systole }\end{array}$ \\
\hline 1 & Poor & $\begin{array}{l}\text { Conical- } \\
\text { cylindrical }\end{array}$ & $\begin{array}{l}\text { More } \\
\text { conical }\end{array}$ & $\begin{array}{l}\text { Subvalvular } \\
\text { infundi- } \\
\text { bular? }\end{array}$ & $10 \mathrm{~mm}$. & $12 \mathrm{~mm}$. & $1 \mathrm{~mm}$. & Almost \\
\hline 2 & Poor & 一* & -* & - & - & - & - & - \\
\hline 3 & Poor & $-\div$ & & -5 & & wider & & Almost \\
\hline $\begin{array}{l}4 \\
5\end{array}$ & $\begin{array}{l}\text { Fair } \\
\text { Fair }\end{array}$ & $\begin{array}{l}\text { Tubular } \\
\text { Tubular }\end{array}$ & $\begin{array}{l}\text { Tubular } \\
\text { Tubular }\end{array}$ & $\begin{array}{l}\text { Infundibular } \\
\text { Infundibular }\end{array}$ & $\begin{array}{l}16 \mathrm{~mm} . \\
4-5 \mathrm{~mm} .\end{array}$ & $\begin{array}{l}2 \mathrm{~mm} . \\
5 \mathrm{~mm} .\end{array}$ & $\begin{array}{l}11 \mathrm{~mm} . \\
11 \mathrm{~mm} \text {. }\end{array}$ & $\begin{array}{l}\text { Not shut } \\
\text { Not shut }\end{array}$ \\
\hline 6 & Fair & Tubular & Tubular & $\begin{array}{l}\text { Valvular, sub- } \\
\text { valvular and } \\
\text { infundibular }\end{array}$ & $5 \mathrm{~mm}$. & $2 \mathrm{~mm}$. & $6 \mathrm{~mm}$. & Almost \\
\hline 7 & Poor & - & & - & - & - & - & \\
\hline 8 & Fair & $\begin{array}{l}\text { Ovaloid, } \\
\text { more } \\
\text { rounded }\end{array}$ & Ovaloid & $\begin{array}{l}\text { Low infundi- } \\
\text { bular and } \\
\text { valvular }\end{array}$ & $20 \mathrm{~mm}$. & $1 \mathrm{~mm} \cdot \dagger$ & $10 \mathrm{~mm} \cdot \dagger$ & Almost \\
\hline $\begin{array}{r}9 \\
10\end{array}$ & $\begin{array}{l}\text { Poor } \\
\text { Fair }\end{array}$ & Conical & Conical & Subvalvular & 5 - & - & - & - \\
\hline & Fair & Conical & Conical & $\begin{array}{l}\text { Subvalvular, } \\
\text { infundibular }\end{array}$ & $5 \mathrm{~mm}$. & $1 \mathrm{~mm}$. & $7 \mathrm{~mm}$. & Almost \\
\hline $\begin{array}{l}11 \\
12\end{array}$ & $\begin{array}{l}\text { Poor } \\
\text { Fair }\end{array}$ & Tubular & Tubular & Valvular & $4 \overline{\mathrm{mm}}$. & $11 \overline{\mathrm{mm}}$. & $18 \overline{\mathrm{mm}}$ & Not shut \\
\hline 13 & Fair & Tubular & Tubular & $\begin{array}{c}\text { Infundibular } \\
\text { hypoplasia }\end{array}$ & $12 \mathrm{~mm}$. & $2 \mathrm{~mm}$. & $6 \mathrm{~mm}$. & Almost \\
\hline $\begin{array}{l}14 \\
15\end{array}$ & $\begin{array}{l}\text { Poor } \\
\text { Fair }\end{array}$ & $\begin{array}{l}\text { Conical } \\
\text { Conical }\end{array}$ & $\begin{array}{l}\text { Conical } \\
\text { Conical }\end{array}$ & $\begin{array}{l}\text { Valvular } \\
\text { Infundibular } \\
\text { subvalvular }\end{array}$ & $\begin{array}{l}6 \mathrm{~mm} . \\
4 \mathrm{~mm} .\end{array}$ & $0^{?}$ & $6 \stackrel{?}{? \mathrm{~mm}}$. & $\begin{array}{l}\text { Not shut } \\
\text { Yes }\end{array}$ \\
\hline 16 & Fair & Conical & Conical & Infundibular & $20 \mathrm{~mm}$. & $1 \mathrm{~mm}$. & $7 \mathrm{~mm}$. & Almost \\
\hline $\begin{array}{l}17 \\
18\end{array}$ & Fair & $\begin{array}{l}\text { Conical } \\
\text { Aplasi }\end{array}$ & Conical & Infundibular & $5 \mathrm{~mm}$. & $1 \mathrm{~mm}$. & $4 \mathrm{~mm}$. & Almost \\
\hline 19 & Fair & Tubular & Conical & $\begin{array}{l}\text { Valvular and } \\
\text { infundibular }\end{array}$ & $20 \mathrm{~mm}$. & $4 \mathrm{~mm}$. & $11 \mathrm{~mm}$. & Not shut \\
\hline $\begin{array}{l}20 \\
21\end{array}$ & $\begin{array}{l}\text { Poor } \\
\text { Poor }\end{array}$ & $\overline{-}$ & 二 & 二 & $=$ & 二 & $=$ & $=$ \\
\hline $\begin{array}{l}22 \\
23\end{array}$ & $\begin{array}{l}\text { Fair } \\
\text { Fair }\end{array}$ & $\begin{array}{l}\text { Conical } \\
\text { Conical }\end{array}$ & $\begin{array}{l}\text { Conical } \\
\text { Conical }\end{array}$ & $\begin{array}{l}\text { Infundibular } \\
\text { Infundibular }\end{array}$ & $\begin{array}{r}6 \mathrm{~mm} . \\
10 \mathrm{~mm} .\end{array}$ & $1 \mathrm{~mm}$. & $\begin{array}{r}13 \mathrm{~mm} . \\
5 \mathrm{~mm} .\end{array}$ & $\begin{array}{l}\text { Almost } \\
\text { Almost }\end{array}$ \\
\hline
\end{tabular}

* In these cases the form could not be judged.

$\dagger$ Infundibular chamber transverse diameter: systolic 21, diastolic $13 \mathrm{~mm}$. 
position. The form and width of the infundibulum are recorded in Table I during maximal ventricular systole and diastole.

The form and calibre of the pulmonary infundibulum demonstrated great variations during the different phases of the cardiac cycle (Fig. 3, 4, 6, and 7). Its form was classified in this series as conical in 11 cases and in most of these the pulmonary stenosis seemed to be infundibular in nature. Four cases showed a tubular or cylindrical form and one of these in particular had a very large infundibular chamber whose form was more rounded or oval in outline (Fig. 3). The contraction of the infundibulum in most of these cases appears to be segmental in nature and mainly subvalvular in type. In only one case of cylindrical form did this contracture appear to involve the entire infundibulum and reduce it to the appearance of a narrow stem.
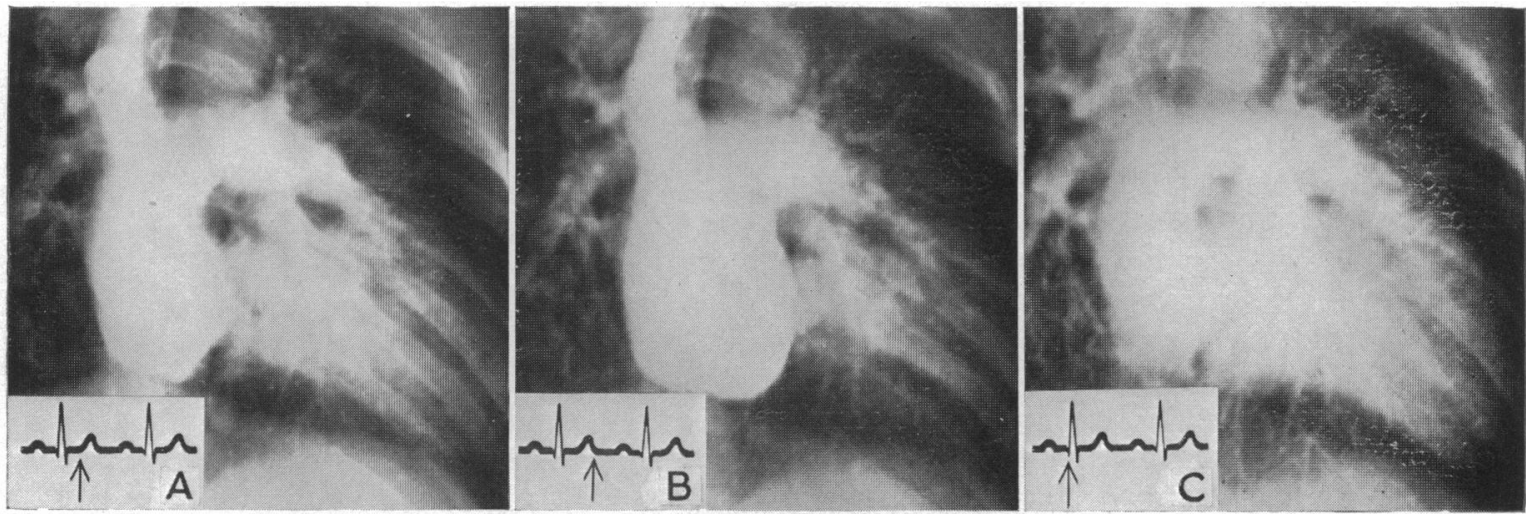

FIG. 5.-A case of infundibular and valvular stenosis. Injection through an antecubital vein (R.A.O.). (A) Superior vena cava dilated. Right ventricle opacified in the middle of systole. There is a moderate narrowing of the infundibulum, followed by a valvular stenosis with a post-stenotic dilation. The infundibulum has a cylindrical form and there is a small globe-like projection of the valvular diaphragms. Aorta is poorly opacified. (B) At the end of systole the moderate contraction with reduction of its calibre can be clearly seen. (C) In the following ventricular diastole the infundibulum is widened and not apparently narrowed any longer, but a post-stenotic dilation can still be seen. The valves cannot be seen, but the pulmonary artery and its branches are well filled with contrast medium.
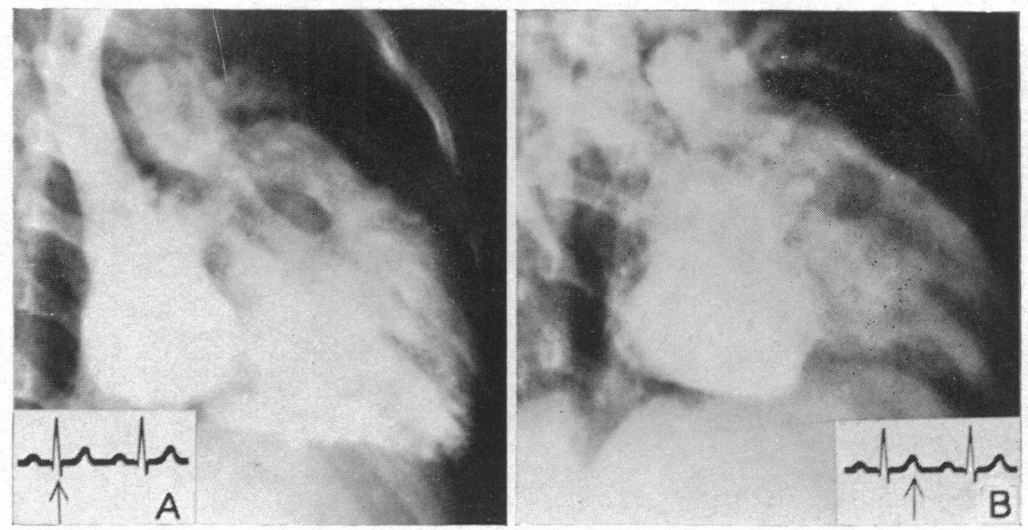

FIG. 6.-Systolic narrowing of the infundibulum (infundibular stenosis). Injection through the left antecubital vein (R.A.O.). (A) Just starting ventricular systole. Infundibulum is a little narrow. Aorta visualized. The lung-fields are clear. (B) In ventricular systole there is a great reduction in calibre of the infundibulum. 
In 3 cases the stenosis or narrowing was considered to be moderate and in another 3 we noted only small variations in the calibre of the infundibulum. In this series we were able to make a probable diagnosis of the nature of the stenosis in 16 cases. In 9 we found infundibular stenosis. In 3 there was unmistakable valvular stenosis (Fig. 4). In another 4 we assumed the presence of a double stenosis, valvular and infundibular in association (Fig. 5). In the remaining 7 it was impossible to decide upon the type of stenosis. It can be clearly seen and demonstrated by means of pictures that the pulmonary infundibulum is not a rigid channel but has its own rhythmic alteration of form. The results in 15 cases in which it was possible to measure different calibres of the pulmonary infundibulum in both systole and diastole, are shown in table form. These figures indicate clearly the various degrees of systolic contraction and the relationship between this contraction and the type of pulmonary stenosis.

Infundibular contraction was questionable in one case with valvular stenosis. The contraction was considered quite marked in 11 cases, with a reduction in diameter to one-third of its original size (Fig. 6). In 10 the infundibulum was almost closed during the ventricular systolic contraction (Fig. 7). Most of these cases showed a conical appearance and infundibular stenosis. In one case there was a moderate dilatation of the infundibulum in ventricular systole-probably due to a more or less complete lack of musculature of the conus.

Pulmonary Artery and its branches. The pulmonary artery and its branches were fairly well silhouetted in 12 cases and in 19 there was a very poor shadow. However, in only one case was it impossible to reach some anatomical conclusions. The main branch always had a horizontal course from its origin in the right ventricle and generally it was short. In 7 cases its relative diameter was considered to be within normal range. In the others, 7 showed different grades of hypoplasia and 6 showed the presence of post-stenotic dilatation. In almost all the left main branch was almost always greater and higher placed than the right one. However, there is no rigid relationship between the calibre of the main stem and the branches of the pulmonary artery in the tetralogy of Fallot. The left branch generally appeared to have the same anatomical characteristics as the main trunk. Nevertheless, in pne case a high degree of hypoplasia of the left branch and an extensive collateral circulation existed and the right main branch had only a moderate reduction of calibre. The peripheral circulation in the lungs was poor in almost all with the exception of Case 4, and the opacification of the lung vessels was prolonged and changed little during the whole series of films.

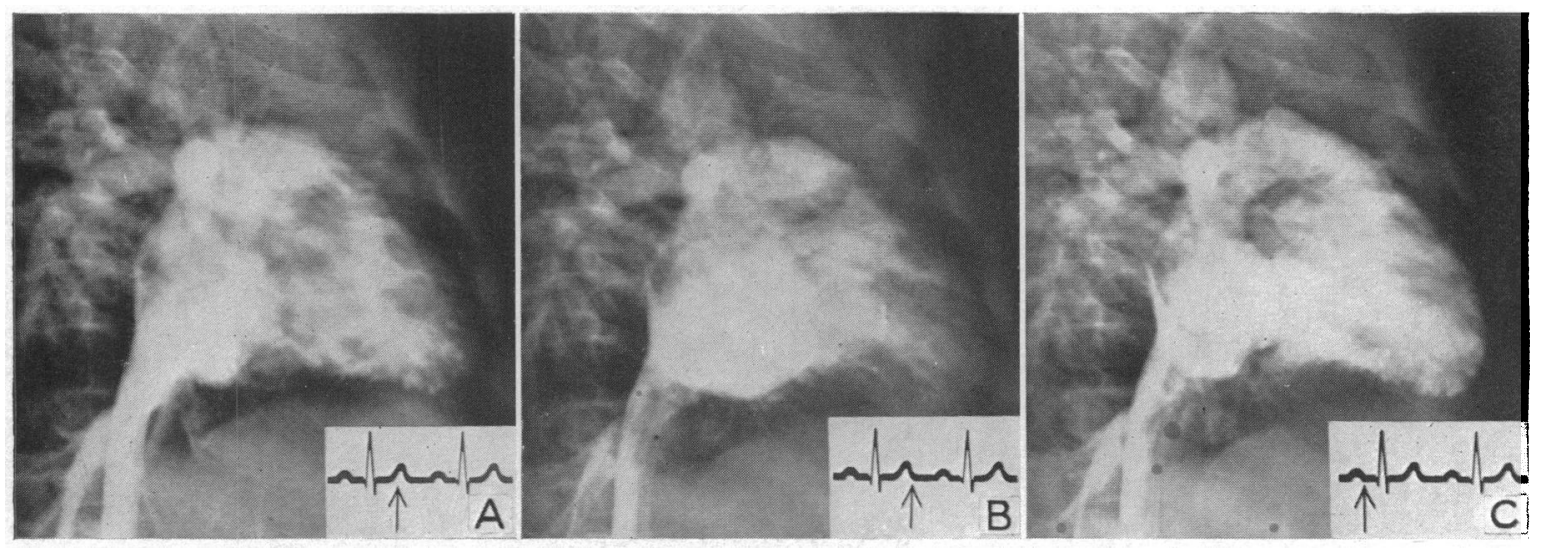

FIG. 7.-Infundibular subvalvular stenosis apparently shut at the end of ventricular systole. Injection through a malleolar vein (R.A.O.). The case was verified at autopsy. (A) In ventricular systole a narrow stenosis of the infundibulum is seen, permitting only a thread-fine stream of contrast to pass. (B) At the end of the same ventricular systole the infundibulum seems to be completely shut in a subvalvular segment. (C) In the following ventricular diastole there is almost a normal passage of dye through the infundibulum. Aorta is poorly contrast filled. 
Left Atrium, Left Ventricle, and the Aorta. Noting the time at which the left atrium fills gives a rough indirect measure of the degree of pulmonary stenosis. Re-opacification in late films of the left side of the heart by contrast medium that has passed through the pulmonary circulation indicates a good pulmonary flow. As a consequence of the diminished flow through the left heart the left atrium and ventricle are often smaller than normal. This may explain why the total heart volume is often not enlarged.

The size of the right-to-left shunt can be roughly estimated by comparison of the amount of contrast medium in the aorta and in the left side of the heart in the left anterior oblique projection. If there is only little overriding and no significant right-to-left intracardiac shunt the early aortic filling may be slight and easy to overlook. This happens less often if two projections are used synchronously. The aorta is more often visible in the projection in which the ascending aorta overlaps the descending aorta.

Early opacification of the aorta was always observed. This generally persisted throughout the greater part of the examination, partly due to the return of dye through the left heart.

Dextroposition of the aorta is of greater degree if its origin appears to be more anterior in the right anterior oblique view. In most cases we found it, however, difficult to delineate accurately the origin of the aorta. (We are using the term dextroposition in its literal and most generally accepted sense rather than its meaning with regard to the anatomical origin of the aorta.) The criteria of an early silhouette for the diagnosis of dextroposition are sometimes unsatisfactory when an atrial septal defect is present, and further, because of the rotation of the heart the projections over the ventricular septum frequently cause mistakes and cannot be relied upon.

In this series the aorta showed great variations in its relative calibre and this apparently bears a relationship to the degree of overriding. With an extreme degree of this the relative calibre was much enlarged and this picture was reversed with a smaller degree of overriding in the origin of the aorta. The course of the aortic arch and the descending aorta was normal in all but two. In one of these there was a left aortic arch with a right-sided descending aorta which is a rare anomaly according to Blalock's experience (Case 2). In the other (Case 14), a right aortic arch was present with a right-sided aorta. In this series we were not able to see the aortic branches clearly because the right anterior oblique projection caused a superimposition of its outlines and the relatively small amount of dye used did not give a well-defined outline of these vessels. In three cases a ductus arteriosus was shown (Fig. 8).

\section{DisCUSSION}

Dilatation of the superior vena cava and right atrium is almost constant. The size of the right atrium as well as of the other heart chambers has been judged in relation to the total heart volume as well as to the other heart cavities.

Only regurgitation of contrast medium into the venæ cavæ during atrial systole has been considered as a true reflux of dye. Reflux during atrial diastole may appear in normal cases as a result of the injection, and has been considered a normal phenomenon following the functional closure of the caval orifices during atrial systole (Hedman et al., 1953).

Evidence of reflux was seen in most cases and most often into the inferior vena cava, for anatomically, as well as functionally, this orifice was considered the weakest point in the right atrium. The dilatation of the right atrium and the true reflux can be considered as evidence of a disturbance of the function of the right atrium. That cardiac catheterization has given normal pressure values in most cases of Fallot's tetralogy can be attributed to the great distensibility of the right atrium. A further sign of impaired function is the increased amount of residual dye at the end of atrial systole, a common finding in our series, noticed especially in cases with interatrial shunts. Generally, the enlargement of the atrium and the increase of the amount of residual dye has been small or moderate. 
The interatrial shunts of dye that have been demonstrated in 8 cases have been from right-toleft in all, and have been noticed in atrial diastole as well as in systole. Sometimes the size of the septal patency can be judged directly, but no attempt was made to carry out an anatomical study of

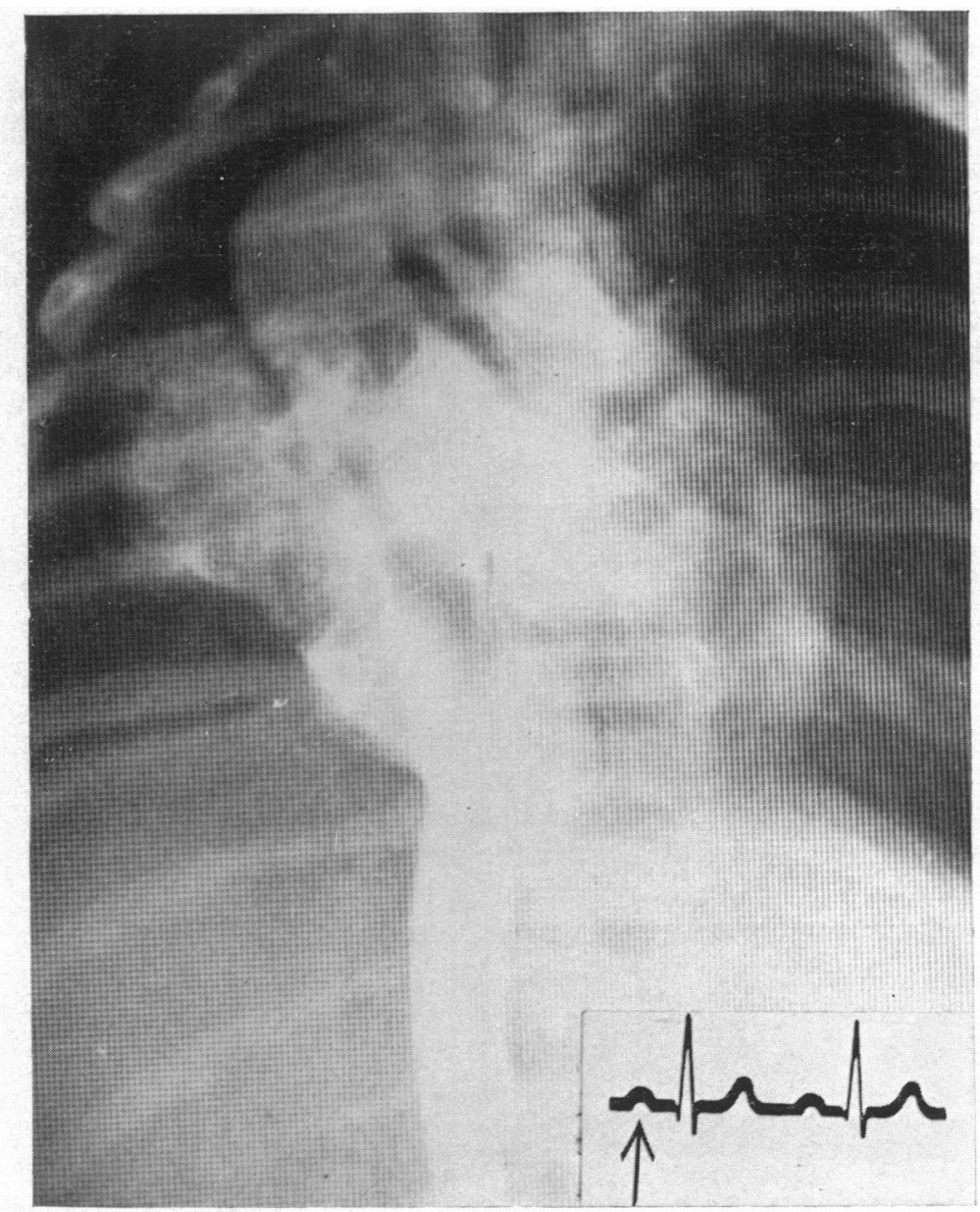

FIG. 8.-Transitory direct visualization of patent ductus (L.A.O.). The patent ductus arteriosus (verified post mortem) is "caught" in ventricular diastole and seen through the aortic window.

these defects. The amount of shunted dye can always be estimated fairly well. Here angiocardiography can be of valuable diagnostic aid. This was discussed in detail in a study of atrial septal patencies with rapid angiocardiography (Lind and Wegelius, 1953).

This high unexpected incidence of atrial septal patency in association with Fallot's tetralogy needs emphasis, because in the past it may not have been sufficiently appreciated. Many patients with this condition have been treated by means of anastomotic procedures with disappointing end results. It is our impression, as previously pointed out, that in view of the different physiology in these cases with large shunts a direct surgical approach should be made on the pulmonary stenosis itself, wherever anatomically possible.

The interventricular shunts, like the interatrial ones, are best seen in the L.A.O. projection and can usually be detected owing to the great difference in dye concentration between the right 
and left side of the heart where the latter as yet contains no contrast medium. Furthermore, when using a rapid series of pictures it is often possible to determine whether the shunt takes place during systole or diastole. The shunts demonstrated have chiefly been directed to the left, in only two cases to the right, and in another two in both directions.

The thickness of the wall of the right ventricle can be well estimated in L.A.O. projection when it forms the margin of the heart during atrial systole. In the R.A.O. projection it can be suspected by the spongy appearance of the contrast medium in the ventricle due to the increased trabeculation of the wall. Judged from these criteria hypertrophy of the right ventricular wall has always been found when the opacification has been satisfactory.

In this small series we have not yet made an attempt to establish the relationship between the degree of right ventricular hypertrophy, the size of interventricular shunts, and the degree of overriding of the aorta. This seems, however, to be possible and appears to be of importance.

The anatomy of the pulmonary infundibulum is not yet settled. From post-mortem findings as well as from external appearance, instrumental exploration, and pressure records during operation, it has been possible for Brock to describe the morphology of the living infundibulum in pulmonary stenosis.

Sellors and Belcher (1950) operated on 65 patients who suffered from Fallot's tetralogy : their impression was that in 45 of these the maximal stenosis was at the infundibulum and in 20 at the pulmonary valve. Burke et al. (1951) studied the anatomy of the sites of obstruction to the pulmonary bloodflow in 48 cases that came to necropsy; in 29 the subpulmonary tract constituted the narrowest point, and 13 of these also showed significant stenosis of the pulmonary valves which was of a lesser degree than that of the infundibulum; in 11 cases the maximal stenosis was in the pulmonary valve and in these was an associated, significant stenosis in the infundibulum in nine. Glower et al. (1952), found at operation that of 30 cases of Fallot's tetralogy the blood flow was obstructed by stenosis at the pulmonary valve in 15; in 6 there was a high infundibular stenosis with an infundibular chamber; in 3 others the stenosis was immediately proximal to the valve and in one there was a low infundibular stenosis. The pulmonary artery was hypoplastic in two cases and finally in three there was a stenosis of the pulmonary artery distal to a normal valve but proximal to the bifurcation of the vessel. Brinton and Campbell (1953) have reported observations from necropsies in 25 patients with Fallot's tetralogy, most were between 7 and 20 years of age. In 10 there was a functional atrial septal defect. Right ventricular hypertrophy was found in every case. The stenosis was infundibular alone in 18 , valvular alone in 2 , and combined infundibular with valvular in 5 , but in a larger series they find valvular stenosis more common than this.

Recently some aspects of Brock's work have been questioned on the basis of post-mortem findings which have rendered doubtful the surgical correction of the pulmonary infundibular stenosis on current anatomical concepts. It has been difficult to substantiate any hypothesis by routine angiocardiographic examination, where the visualization of the infundibulum is not complete. By injecting the contrast-medium chiefly into right ventricle or if possible into the pulmonary artery (Chavez, 1947; Jönsson, 1949), it is possible to obtain a more complete picture of the anatomy of the outflow tract of right ventricle, the pulmonary artery, and the overriding aorta and its main branches, but not of the physiology which may be disturbed by the presence of the catheter and the injection under high pressure. A further limitation of this way of introducing the contrast medium is that it cannot give full information about the presence of other associated congenital malformations of the heart. A prerequisite for a good result is to use rapid biplane photography with simultaneous recording of the electrocardiogram.

With rapid angiocardiography it is possible to see in serial pictures the different phases of physiology of the infundibulum in the cardiac cycle and following intravenous injection of the contrast medium the pressure relations may not be disturbed. Most of our observations agree with Brock and Campbell's (1950 $\mathrm{b}$ ) descriptions of the form of infundibulum. A complete change of form of the infundibulum during systole and diastole could usually be seen. The tubular or cylindrical appearance can change to a conical form following a stronger segmental contraction. 
The actual site of stenosis in most cases was subvalvular and for this reason a conical appearance would be accentuated during systole. We have also found the infundibular chamber and its variation in calibre during ventricular systole to be a function of its position with reference to the valve. The " segmental" contraction of the infundibulum may be emphasized in view of its surgical importance. This type could be verified in most cases; in only one was contraction of the entire infundibulum observed in which its form was changed to a narrow stem in agreement with Soulie's description. The systolic contraction of the infundibulum was clearly greater in infundibular than in valvular stenosis, and sometimes was sufficient to cause an apparent complete shutting off of the infundibulum or at least an extraordinary reduction of its calibre (see Table I). This was shown in Case 22 where the diastolic diameter was reduced from $13 \mathrm{~mm}$. to a systolic diameter of $1 \mathrm{~mm}$. However, in cases of co-existing valvular stenosis these contractions do not produce a significant reduction of the calibre of the infundibulum: there does not appear to be very much poststenotic dilation of the pulmonary trunk and its branches as can be seen in pure pulmonary valvular stenosis. The reason for this difference and the absence of an increased globe-like projection of the pulmonary valve may be explained by the relatively moderate infundibular stenosis which limits the impact of the total pressure gradient of the right ventricle against the stenosed valve. This may explain why pulmonary valvotomy in Fallot's tetralogy does not transform this condition into an Eisenmenger complex, the relatively " moderate" grade of infundibular stenosis regulating the transmission to the ventricular pressure to the pulmonary vessels during systolic contraction and acting as a sort of protective mechanism.

From an anatomical point of view the direct surgical correction of infundibular stenosis appears to be feasible in selected cases. This group includes the " segmental " type of infundibular stenosis (high subvalvular, intermediate, or low infundibular positions) and this represents in our material and from other reports possibly up to 60 per cent of all cases of infundibular stenosis. In the remaining group in which the stenosis involves the entire infundibulum, surgical correction does not appear to be feasible. Another approach would be to achieve maintenance of the diastolic calibre of the infundibulum in some of these cases, which we are now attempting to do experimentally.

This discussion on the direct surgery or pulmonary stenosis is meant to focus attention on the anatomical possibilities of correction and does not imply preference for such technique, since if this is to be done the functional pathology of each particular case must be considered.

\section{Summary AND CONCLUSIONS}

A study has been made of 23 cases of Fallot's tetralogy with rapid angiocardiography and simultaneous electrocardiographic recording. The different mechanisms of the venous return to the heart are discussed. There is always enlargement of the right heart with hypertrophy of the right ventricle.

Right-to-left shunts can be demonstrated with this technique. Right-to-left interatrial shunts occurred in 8 out of 23 cases. Right-to-left interventricular shunts occurred in most of the cases.

Strong systolic contractions of the pulmonary infundibulum were shown in most of the cases. In the presence of valvular stenosis in Fallot's tetralogy there was often " relative " or " functional " moderate infundibular stenosis.

It must be emphasized that the calibre of the infundibulum varies with the phase of the heart cycle. It depends on functional as well as anatomical factors, and an infundibular stenosis observed when the heart is in ventricular systole does not necessarily mean an organic stenosis. The exact nature of the outflow tract of the right ventricle can be completely understood only by comparing films from full systole and full diastole and enough intermediate phases. 
The presence of interatrial shunts in Fallot's tetralogy should be looked for since they may influence the choice of surgical treatment. Pre-operative study may show the nature of the pulmonary stenosis.

Anatomical correction by direct pulmonary surgery may be possible in a large number of selected cases of Fallot's tetralogy.

This paper was presented at the Scientific Meeting of the Middle Tennessee Heart Association, Vanderbilt University, Nashville, in April, 1953.

\section{REFERENCES}

Blalock, A. (1948). Surg. Gyn. Obst., 87, 385.

Blalock, A., and Kieffer, R. F. (1950). Ann. Surg., 132, 496.

Brinton, W. D., and Campbell, M. (1953). Brit. Heart J., 15, 335.

Brock, R. C. (1948). Brit. med. J., 1, 1121.

- (1949). Brit. med. J., 2, 399.

- (1952). Amer. J. Med., 12, 706.

- and Campbell, M. (1950a). Brit. Heart J., 12, 377.

,$- \quad(1950 b)$. Brit. Heart J., 12, 403.

Burke, E. C., Kirklin, J. W., and Edwards, J. E. (1951). Staff Meetings Mayo Clinic, 26, 498.

Chavez, I., Dorbecker, N., and Celis, A. (1947). Amer. Heart J., 33, 560.

Donzelot, E., D’Allaines, F., Dubost, Ch., Metianu, C., Durand, N., and Dubost, C. (1952). Semaine Hôp., Paris, 28, 877 .

Fredzell, G., Lind, J., Ohlson, E., and Wegelius, C. (1950). Amer. J. Roentgenol., $63,548$.

Glover, R. P., Bailey, C. P., O'Neill, T. J. E., Downing, D. F., and Wells, C. R. E. (1952). J. Thoracic Surg., 23, $14-41$. Hedman, Ch., Lind, J., and Wegelius, C. (1953). Brit. Heart J., 15, 143.

Hilario, J., and Carvacho, A. A. (1952). The Physiopathology of Tetralogy of Fallot. Presented to National Academy of Medicine, Brazil.

Johnson, F. (1953). Personal communication.

Lind, J., and Wegelius, C. (1953). Medicine Illustrated, 4, 135.

Lowe, J. B. (1953). Brit. Heart J., 15, 319.

Jönsson, G., Brodén, B., and Karnell, J. (1949). Acta radiol., 32, 486.

Lind, J., and Wegelius, C. (1953). Circulation, 7, 819.

- (1952). Advances in Pediatrics, Vol. V. 154.

Metianu, C. (1953). Personal communication.

Saverne, J. (1951). These de Lyon.

Sellors, T. H., and Belcher, J. R. (1950). Lancet, $2,887$.

Soulié, P., Chiche, P., and Voci, G. (1951). Semaine Hôp., Paris, 27, 734. 